\title{
Observations of the relationship between sprite morphology and in-cloud lightning processes
}

\author{
Oscar A. van der Velde, ${ }^{1}$ Ágnes Mika, ${ }^{2}$ Serge Soula, ${ }^{1}$ Christos Haldoupis, ${ }^{2}$ \\ Torsten Neubert, ${ }^{3}$ and Umran S. Inan ${ }^{4}$ \\ Received 10 November 2005; revised 30 March 2006; accepted 25 April 2006; published 4 August 2006.
}

[1] During a thunderstorm on 23 July 2003, 15 sprites were captured by a LLTV camera mounted at the observatory on Pic du Midi in the French Pyrénées. Simultaneous observations of cloud-to-ground (CG) and intracloud (IC) lightning activity from two independent lightning detection systems and a broadband ELF/VLF receiver allow a detailed study of the relationship between electrical activity in a thunderstorm and the sprites generated in the mesosphere above. Results suggest that positive CG and IC lightning differ for the two types of sprites most frequently observed, the carrot- and column-shaped sprites. Column sprites occur after a short delay $(<30 \mathrm{~ms})$ from the causative $+\mathrm{CG}$ and are associated with little VHF activity, suggesting no direct IC action on the charge transfer process. On the other hand, carrot sprites are delayed up to about $200 \mathrm{~ms}$ relative to their causative +CG stroke and are accompanied by a burst of VHF activity starting $25-75 \mathrm{~ms}$ before the CG stroke. While column sprites associate with short-lasting (less than $30 \mathrm{~ms}$ ) ELF/VLF sferics, carrot sprites associate with bursts of sferics initiating at the time of the causative $+\mathrm{CG}$ discharge and persisting for 50 to $250 \mathrm{~ms}$, indicating extensive in-cloud activity. One carrot event was found to be preceded by vigorous IC activity and a strong, long-lived cluster of ELF/VLF sferics but lacking a $+\mathrm{CG}$. The observations of ELF/VLF sferic clusters associated with lightning and sprites form the basis for a discussion of the reliability of lightning detection systems based on VHF interferometry.

Citation: van der Velde, O. A., Á. Mika, S. Soula, C. Haldoupis, T. Neubert, and U. S. Inan (2006), Observations of the relationship between sprite morphology and in-cloud lightning processes, J. Geophys. Res., 111, D15203, doi:10.1029/2005JD006879.

\section{Introduction}

[2] Sprites are transient luminous events (TLE) of less than $\sim 100 \mathrm{~ms}$ duration ocurring above active thunderstorms in the mesosphere in the 40-90 km altitude range [e.g., Neubert, 2003]. Although predicted 80 years ago [Wilson, 1925] it is only during the last 15 years that TLEs have been known to the scientific community [Franz et al., 1990]. On the basis of simultaneous observations of cloud-to-ground (CG) lightning activity and sprites it is now generally accepted that positive cloud-to-ground flashes $(+\mathrm{CG})$ trigger sprites [Boccippio et al., 1995; Lyons et al., 2003a] provided they are characterized by sufficiently large charge moment changes (typically 200$1500 \mathrm{C} \mathrm{km}$ ) [Williams, 1998; Hu et al., 2002; Lyons et al., 2003b; Cummer and Lyons, 2005].

[3] The most commonly accepted theories of sprite generation invoke the quasi-electrostatic field generated in the stratosphere and mesosphere following a $+\mathrm{CG}$ discharge [Pasko et al., 1997]. However, alternative theories suggest

\footnotetext{
${ }^{1}$ Université Paul Sabatier, Toulouse, France.

${ }^{2}$ University of Crete, Department of Physics, Heraklion, Crete, Greece.

${ }^{3}$ Danish National Space Center, Copenhagen, Denmark.

${ }^{4}$ STAR Laboratory, Stanford University, Stanford, California, USA.
}

Copyright 2006 by the American Geophysical Union. 0148-0227/06/2005JD006879 an important role for the field generated by horizontal lightning currents [Valdivia et al., 1997; Rycroft and Cho, 1998].

[4] In this paper, the term intracloud (IC) lightning activity is not meant to describe a separate class of flashes as opposed to cloud-to-ground (CG) flashes, but refers to all phases of lightning in the cloud or air involved during one flash event, including leader activity accompanying a CG flash. While the importance of IC lightning in the sprite generation process is little known, primarily due to lack of measurements by lightning detection networks, indirect evidence suggests that it may also play a part. For instance, the time delays between the causative $+\mathrm{CG}$ and the sprite may extend to beyond $100 \mathrm{~ms}$ [Bell et al., 1998; Füllekrug and Reising, 1998; Mika et al., 2005], suggesting that the electric field in the mesosphere builds up over time as a result of the charge redistribution mediated by the continuing current of the $+\mathrm{CG}$ and the IC currents feeding it. Furthermore, sprites may be horizontally displaced up to $50 \mathrm{~km}$ from the +CG discharge [Wescott et al., 2001; São Sabbas et al., 2003] possibly as a result of horizontally extended IC lightning channels.

[5] In recent years, three-dimensional lightning mapping systems have aided greatly in identifying processes of sprite-generating lightning flashes. In a storm system in Florida, sprites were found to occur at the periphery of 
expanding horizontal cloud discharges ('spider lightning'), shortly after a $+\mathrm{CG}$ was produced [Stanley, 2000]. The intracloud discharge in these cases continued after the $+\mathrm{CG}$ to last up to several seconds and spanned tens of kilometers. The height of charge removal was at $7-8 \mathrm{~km}$, higher than was found for High Plains storms [Lyons et al., 2003b] during the STEPS field campaign [Lang et al., 2004a] in the summer of 2000, when the +CGs only produced sprites when the maximum of VHF sources at $8 \mathrm{~km}$ weakened and a secondary, lower-level $(2-5 \mathrm{~km})$ maximum started to develop.

[6] Further observational evidence comes from very low frequency (VLF) and extremely low frequency (ELF) observations suggesting that strong IC activity may be associated with sprites [Ohkubo et al., 2005].

[7] In this paper we present one of the first direct observations of intracloud lightning simultaneously with optical observations of sprites. We explore the association between sprites and the lightning activity and find distinct differences between activity related to column and carrot sprites. Finally, the data set forms the basis for a discussion of the differences (and difficulties) in IC lightning registration by a very high frequency (VHF) lightning detection system and a nearby ELF/VLF broadband receiver.

\section{Instrumentation}

[8] During July and August 2003, the EuroSprite 2003 campaign brought together several instruments in order to investigate the origin and effects of sprites [Neubert et al., 2005]. Sprites were detected with a light-sensitive camera system mounted at the Observatoire Midi-Pyrénées on Pic $\mathrm{du}$ Midi in the French Pyrenees $\left(42.93^{\circ} \mathrm{N}, 0.14^{\circ} \mathrm{E}\right)$ at $2877 \mathrm{~m}$ altitude. The system was controlled remotely over the Internet and included automated event detection for reduction of the data volume. The frame integration time was $20 \mathrm{~ms}$ and the system time was correct to within $12 \mathrm{~ms}$.

[9] Data from two different lightning detection systems were used to obtain accurate positions and timing of CG and IC lightning. The large French lightning detection network run by Météorage adopts 17 sensors using both direction finding and time of arrival techniques to determine the location of positive and negative CG strokes over the entire country [Cummins et al., 1998]. The detection efficiency is $\sim 90 \%$ and the network provides the location, time, stroke multiplicity, and peak current of each detected CG flash. The second lightning detection system, SAFIR, can detect the total (CG and IC) lightning activity over a limited area in southeastern France. It consists of three stations in a triangular configuration with a baseline of a few hundred kilometers, each station detecting the direction of $\mathrm{VHF}$ radio emissions from lightning flashes by interferometry. SAFIR provides the two-dimensional (2-D) source location (horizontal only) by triangulation methods with a $100 \mu \mathrm{s}$ time resolution [Richard and Lojou, 1996].

[10] Sprite-producing thunderstorms traversed the area covered by the SAFIR system on three nights. The bestquality data were obtained during the night of 23-24 July 2003, when the sprite-producing region of a mesoscale convective system (MCS) was in the range of detection. During this night, SAFIR had only two operational antennas, which caused lightning signals originating from a small area between the antennas not to be accurately determined and therefore dismissed by the system. This detection gap of the SAFIR network could have affected events 10,11, and 12 (Table 1), with +CG strokes occurring near the edges of the gap. SAFIR sources were detected for some of these strokes, but the sprite-producing second $+\mathrm{CG}$ strokes of events 11 and 12 must have occurred in this gap.

[11] Observations of broadband ELF/VLF activity were available from a receiver located at Nançay $\left(47.38^{\circ} \mathrm{N}\right.$, $\left.2.19^{\circ} \mathrm{E}\right)$, near Orleans, France. The system uses two large triangular magnetic loop antennas measuring the N-S and E$\mathrm{W}$ components in the band $\sim 350 \mathrm{~Hz}$ to $45 \mathrm{kHz}$. The analog outputs of the two channels are sampled at $100 \mathrm{kHz}$ and the system uses GPS-based timing. It has been shown that the detection efficiency of broadband ELF/VLF receivers is $100 \%$ for CG discharges [Wood and Inan, 2002]. The ELF/VLF measurements are therefore useful for identification of CG flashes possibly missed by the lightning detection networks. In addition, at short distances from the receiver (within about $500 \mathrm{~km}$ ) one would expect the ELF/VLF system to detect sferics originating from IC lightning [Johnson and Inan, 2000; Ohkubo et al., 2005].

\section{Observations}

[12] During the night of 23-24 July 2003, 15 sprite events were captured by the camera at Pic du Midi. For the events of this night we had minimal difficulty classifying the type of a sprite: they almost all obeyed the classic shapes of columns (narrow, straight, short, mostly uniform elements) or carrots (taller, irregular shapes, usually with very visible streamers extending upward and downward from a bright core). Examples of observed sprites are shown in Figure 1. On the left there is a cluster of three sprites of the carrot type, with tendrils extending downward and upward, in the middle a cluster of column type sprites of single column emissions, and on the right one carrot sprite event for which no causative $+\mathrm{CG}$ could be identified. The three cases in Figure 1 are discussed in more detail in the following.

\subsection{Meteorological Development}

[13] A mesoscale convective system developed in the early evening of 23 July 2003 north of the Pyrenees, around 1600 UTC. Initially the system was a mere clustering of cells surrounded by stratiform precipitation regions, but as a cold pool formed the system developed more of a leading line-trailing stratiform configuration, but not very steady. About 2 hours before the first sprite the system developed a northern and a southern convective region. The first sprite was observed at 2111 UTC as portions of the northern convective region started to weaken quickly. A radar image of this part of the storm is shown in Figure 4. During this episode, which lasted for an hour, events 1-8 occurred. Events 9-12 happened when the southern convective region weakened, around 2300 UTC. The system assumed a spiral shape (developing a Mesoscale Convective Vortex) at this time, with the higher reflectivities and sprites near the center. At a stronger portion of the eastern arm of remaining reflectivity, three sprites $(13-15)$ happened an hour later, just before the system had completely dissolved.

[14] The size of the northern portion of the storm system with radar reflectivities greater than $>10 \mathrm{dBZ}$ was about 
Table 1. Sprites Observed on 23-24 July 2003 and Their Parent Lightning Activity Characteristics Inferred From the Météorage and SAFIR Systems and a Nearby Broadband VLF Receiver ${ }^{\mathrm{a}}$

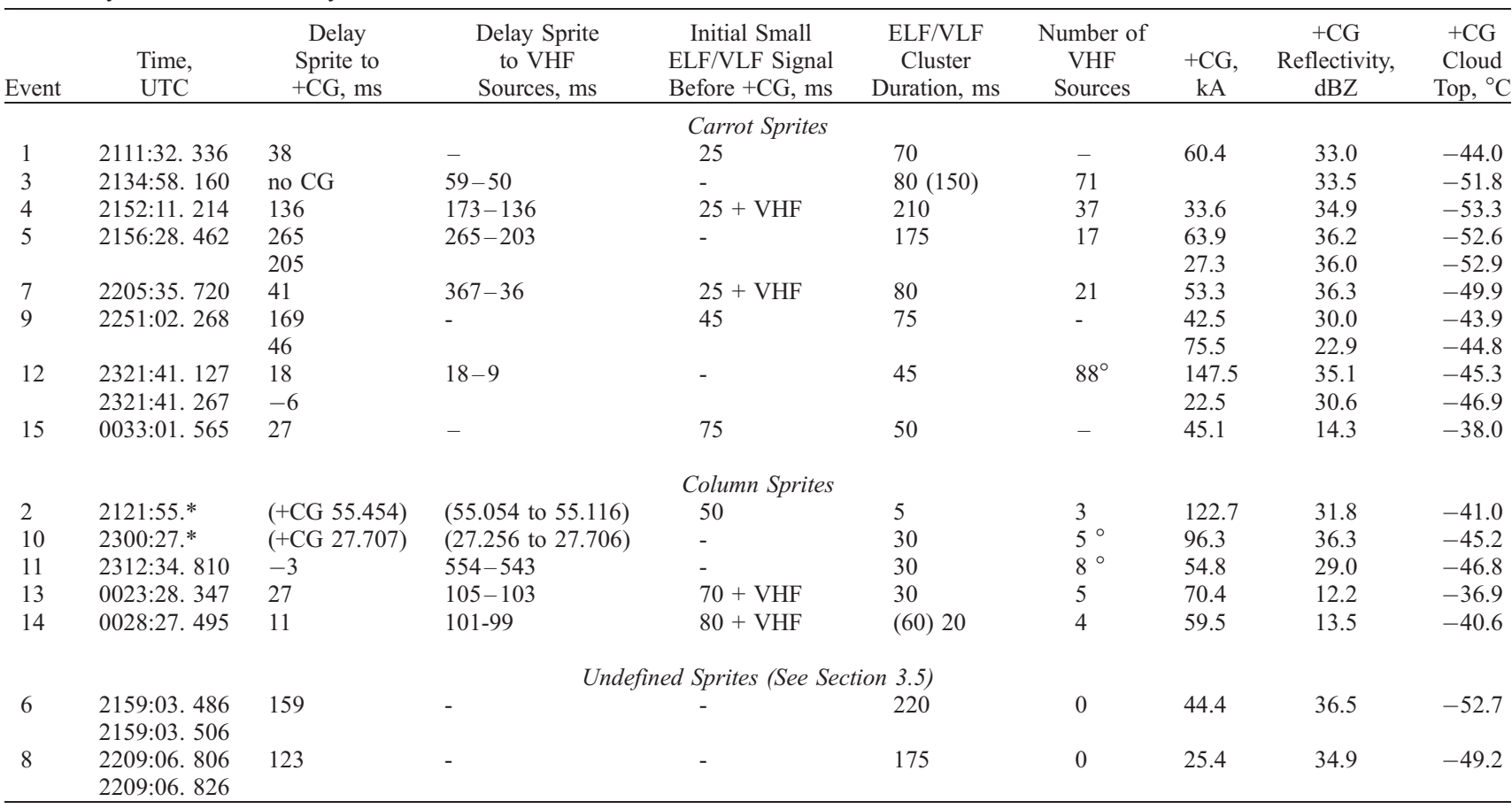

${ }^{a}$ Here asterisk indicates precise time unknown; long dash indicates likely lacking VHF detection at longer range; open circle indicates may have been affected by SAFIR gap (see instrumentation section). ELF/VLF cluster (strongest part) duration time in parenthesis means there exists an uncertainty about the relevant cluster duration (in event 3 about the end, in event 14 about the start). Reflectivities and cloud top temperatures are taken as an average within a radius of $10 \mathrm{~km}$ from the parent $+\mathrm{CG}$ stroke.

$20,000 \mathrm{~km}^{2}$ during the occurrence of sprites, while at the same time reflectivity areas greater than $40 \mathrm{dBZ}$ in the convective region amounted only to $1000-1500 \mathrm{~km}^{2}$. The maximum reflectivity in the storm decreased from $63 \mathrm{dBZ}$ at the time of the first sprite to $48 \mathrm{dBZ}$ at the time of the last sprite. The total reflectivity area reached about $40,000 \mathrm{~km}^{2}$ already before sunset at 1923 UTC. The total shield of cloud tops colder than $-30^{\circ} \mathrm{C}$ reached an area of $50,000 \mathrm{~km}^{2}$, while the area colder than $-50^{\circ} \mathrm{C}$ reached its maximum of $17,000 \mathrm{~km}^{2}$ at $2130 \mathrm{UTC}$. Compared to sprite-producing storms over the High Plains of the United States [Lyons et $a l ., 2006]$, our storm system had relatively small horizontal and vertical dimensions but met the minimum parameter preconditions observed there.

[15] The coldest cloud tops during the sprite occurrences around $-54{ }^{\circ} \mathrm{C}$ (the tropopause level according to the soundings), while sprites appeared over areas of cloud tops warmer by $2-16$ degrees, consistent with the findings of Lyons et al. [2006]. The average reflectivity values in a circle with a radius of $10 \mathrm{~km}$ around a sprite-producing $+\mathrm{CG}$ were very uniform among the sprites, generally between 30 and $35 \mathrm{dBZ}$. There appear to be no meaningful differences in reflectivity or cloud top temperature values between carrot and column sprites in the data set of this paper. An upcoming paper will discuss in more detail the statistics on meteorological properties and CGs of spriteproducing storms in France.

\subsection{Column Sprite Events}

[16] The observed sprites and the associated lightning as recorded by the various systems are listed in Table 1 . Events with the least associated VHF IC sources detected by the

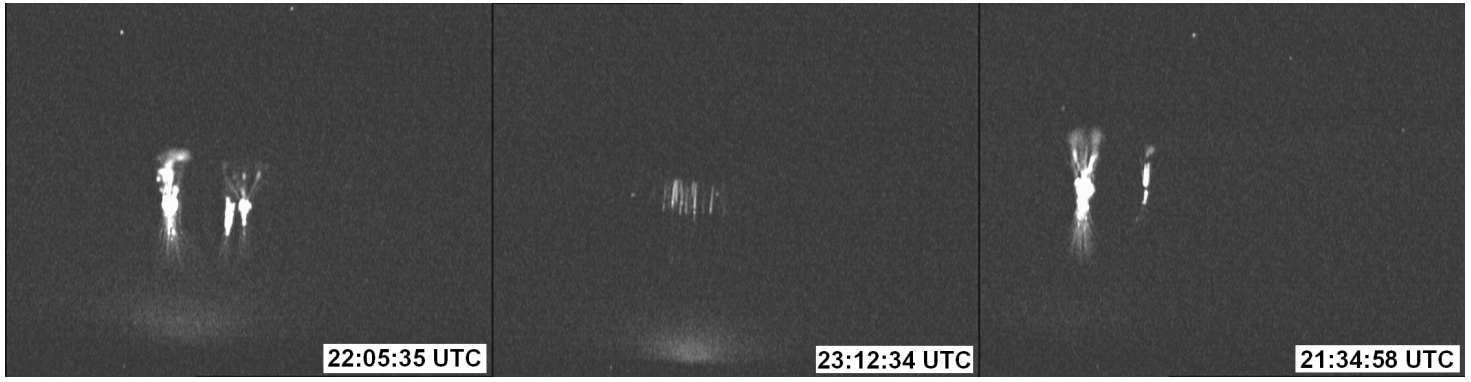

Figure 1. Examples of observed sprites: (left) Carrots 2205:35 UTC; (middle) columns 2312:34 UTC; (right) carrot without detected parent $+\mathrm{CG}, 2134: 58$ UTC. 

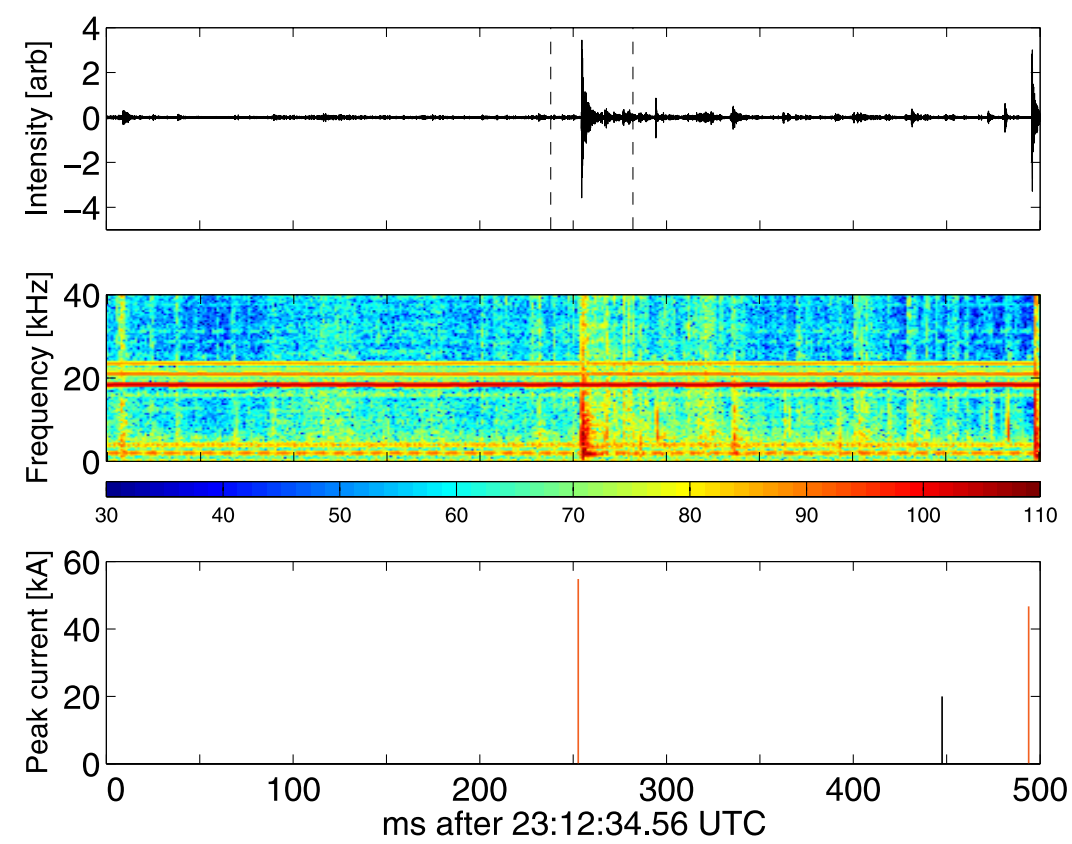

Figure 2. Broadband ELF/VLF waveforms (top) and the corresponding spectrum (middle, dB), $250 \mathrm{~ms}$ before and after the column sprite event of 23 July 2003, 2312:34 UTC (Figure 1, middle). Displayed is the east-west component of the signal. The two vertical dashed lines indicate the sprite observation time, accounting for the video frame integration time of $20 \mathrm{~ms}$ plus the time uncertainty of $12 \mathrm{~ms}$. The bottom panel shows Météorage cloud-to-ground strokes (red) and SAFIR VHF lightning sources (black). The vertical scale indicates the $+\mathrm{CG}$ peak current $(\mathrm{kA})$. The lengths of the black lines representing the SAFIR data are scaled arbitrarily. The units of the top panel waveforms are arbitrary after filtering out noise.

SAFIR system (3 to 8 sources: events $2,10,11,13$, and 14) were all column sprites. In these cases, the spatially clustered sources occurred up to several hundred milliseconds before the causative $+\mathrm{CG}$ flashes. On the other hand, the lag times between +CGs and the column sprites were short, between -3 and $+27 \mathrm{~ms}$ (average $12 \mathrm{~ms}$ ) relative to the start of the video frame integration time of $20 \mathrm{~ms}$. Events 2 and 10 were retrieved from the video files with less temporal accuracy. However, the parent $+\mathrm{CG}$ flash and the sprite of event 10 was visible in the same video frame, so the delay must have been smaller than $20 \mathrm{~ms}$. Event 2 followed in the first frame after a bright flash, so this delay ranged anywhere between $\sim 1$ and $40 \mathrm{~ms}$.

[17] The approximate average and median duration of ELF/VLF sferic clusters was about 25-30 ms for column sprites. The clusters started with the $+\mathrm{CG}$ return stroke and the waveform amplitudes decreased exponentially with time for nearly all the events. The single small column event at 2121 UT did not have a clearly recognizable long-lasting sferic cluster. Figure 2 shows the ELF/VLF-broadband sferic cluster and the VHF sources associated with event 11 (2312 UTC; Figure 1, middle). Here, the burst of ELF/ VLF sferic energy is short (about $30 \mathrm{~ms}$ ) while the delay between the $+\mathrm{CG}$ and the sprite is of the same order. The Météorage network detected a $+\mathrm{CG}$ stroke $(54.8 \mathrm{kA})$ within the $20 \mathrm{~ms}$ video frame integration time that contained the sprite, and, as shown in Table 1, this appears to be typical of all observed column sprites. In this case, SAFIR only detected a small cluster of 8 sources about $550 \mathrm{~ms}$ before the sprite, which may be too early to be associated with the charge transfer process that triggered the sprite.

\subsection{Carrot Sprite Events}

[18] The events with the largest number of associated VHF IC sources, (17 to 88 sources: events $3,4,5,7$, and 12) were all carrot sprites. The VHF sources were clearly related in time to the sprite-causative $+\mathrm{CG}$ flash, except for event 3 where no $+\mathrm{CG}$ flash was identified. It is remarkable that the delay between the +CGs and the sprites was 18-205 ms, which is much longer than for column sprites, with an average value of $63 \mathrm{~ms}$ (median: $39.5 \mathrm{~ms}$ ). The duration of the ELF/VLF sferics was also longer with averages of $100-$ $110 \mathrm{~ms}$ (median 75-80 ms).

[19] Figure 3 shows the ELF/VLF broadband sferic cluster and the VHF sources associated with event 7 (2205 UTC; Figure 1, left), which occurred in the same portion of the storm as events $4-8$. It was accompanied by a burst of 21 VHF sources, all happening before the causative $+\mathrm{CG}$ discharge. The return stroke is well defined in the ELF/VLF waveforms as a brief pulse of strong power particularly intense at the lowest frequencies $(<5 \mathrm{kHz})$. The isolated cluster of VHF sources, at about $20 \mathrm{~ms}$ prior to the $+\mathrm{CG}$ discharge, occurred simultaneously with a weak burst of broadband ELF/VLF noise. On the other hand, the ELF/VLF sferics following the return stroke are not accompanied by any lightning detected by the Météorage and the SAFIR systems. The carrot sprite was triggered during the period of high sferic activity at least $30 \mathrm{~ms}$ after the $+\mathrm{CG}$. 

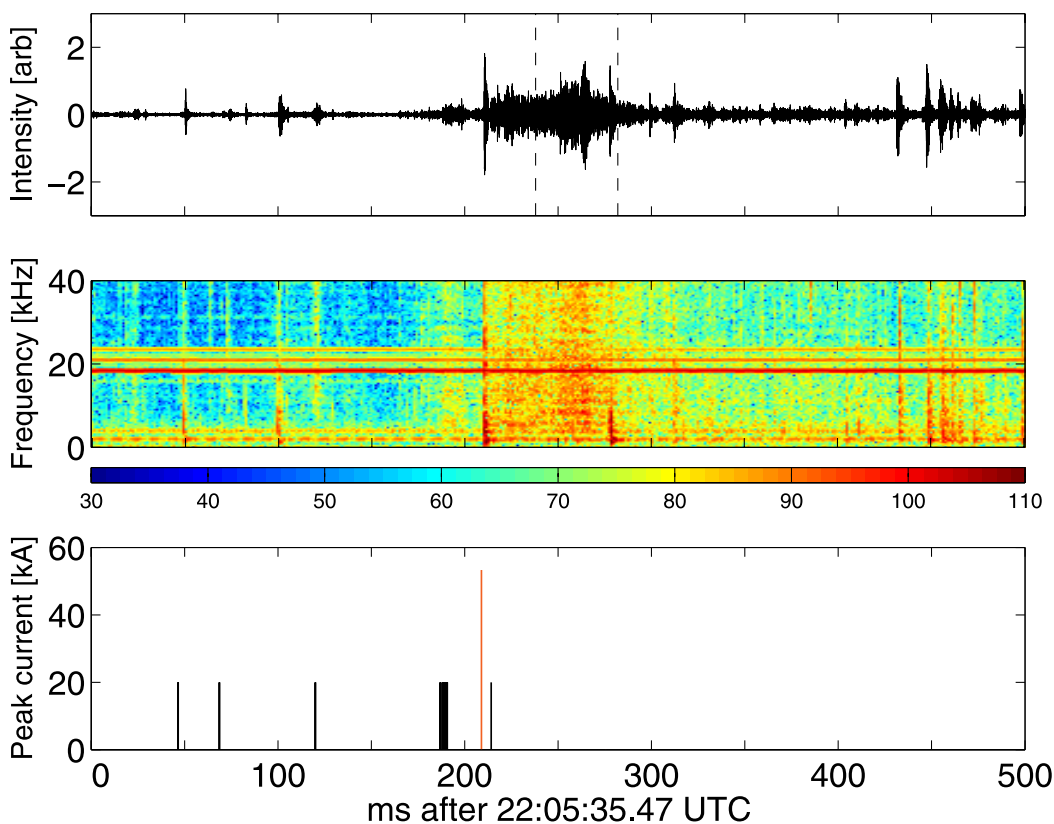

Figure 3. Same as in Figure 2 but for the carrot sprite event of 23 July 2003, 2205:35 UTC (Figure 1, left). Displayed is the east-west component of the signal.

The situation described above was typical for most of the carrot events of Table 1.

[20] We remark that we classified event number 12 with certainty as a carrot sprite, but a regular pattern of straight vertical elements in the top parts of the carrots occurs as well, especially in the second frame, which is somewhat reminiscent of columns. This event also features the shortest delay among the carrot sprites, and the sprites in the two frames were produced by two separate +CGs.

\subsection{A Sprite Without a Causative CG Flash}

[21] The two carrot sprites of event 3 (2134:58 UTC; Figure 1, right) could not be associated with a $\mathrm{CG}$ flash by either of the two lightning detection systems. However, the SAFIR system recorded a burst of $71 \mathrm{VHF}$ sources prior to the event, the second-largest VHF burst seen on that night. Figure 4 shows the locations of all detected sources during the one second period centered around the event overlaid on a map of weather radar reflectivity and infrared cloud-top temperature. Also shown is the direction of the two sprites as seen from Pic du Midi. The direction toward the larger sprite passes near the VHF cluster (white diamonds) which has a spatial extent of $\leq 12 \mathrm{~km}$. The smaller sprite curves at the bottom toward the clouds illuminated by IC activity and probably traces the direction of the electric field from the source region in the clouds [Neubert et al., 2005]. The sources are located near the highest cloud tops in a portion of the stratiform region with relatively high radar reflectivity, due to a decay of a part of the convective region in this area half an hour before the sprite. The burst of VHF sources lasted for $9 \mathrm{~ms}$ and ended $50 \mathrm{~ms}$ before the sprite. Two -CG strokes (white squares) occurred about $500 \mathrm{~ms}$ before the sprites at $\sim 15 \mathrm{~km}$ distances from the VHF source region. This time difference is probably too long for the flashes to be related to the sprites, besides the overall unlikelihood of sprite-generation by -CGs. Other studies

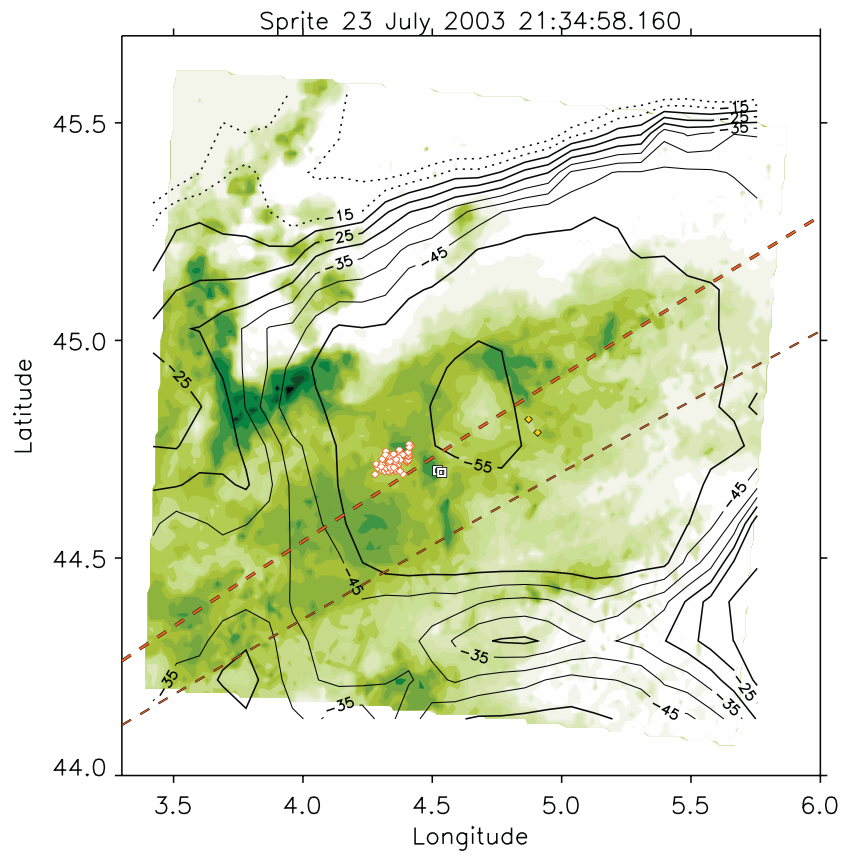

Figure 4. Thunderstorm conditions during the carrot sprite event observed on 23 July 2003, 2134:58 UTC (Figure 1, right). Directions of the two sprites seen from the Pic du Midi (dashed lines) are overlaid on radar reflectivity (shaded in green), infrared cloud top temperature (contour lines, ${ }^{\circ} \mathrm{C}$ ) and $1 \mathrm{~s}$ of lightning activity (squares: $-\mathrm{CG}$; diamonds: VHF sources). Lightning activity highlighted in white occurred within $500 \mathrm{~ms}$ before the sprite, and lightning activity displayed in yellow occurred within $500 \mathrm{~ms}$ after the sprite. 

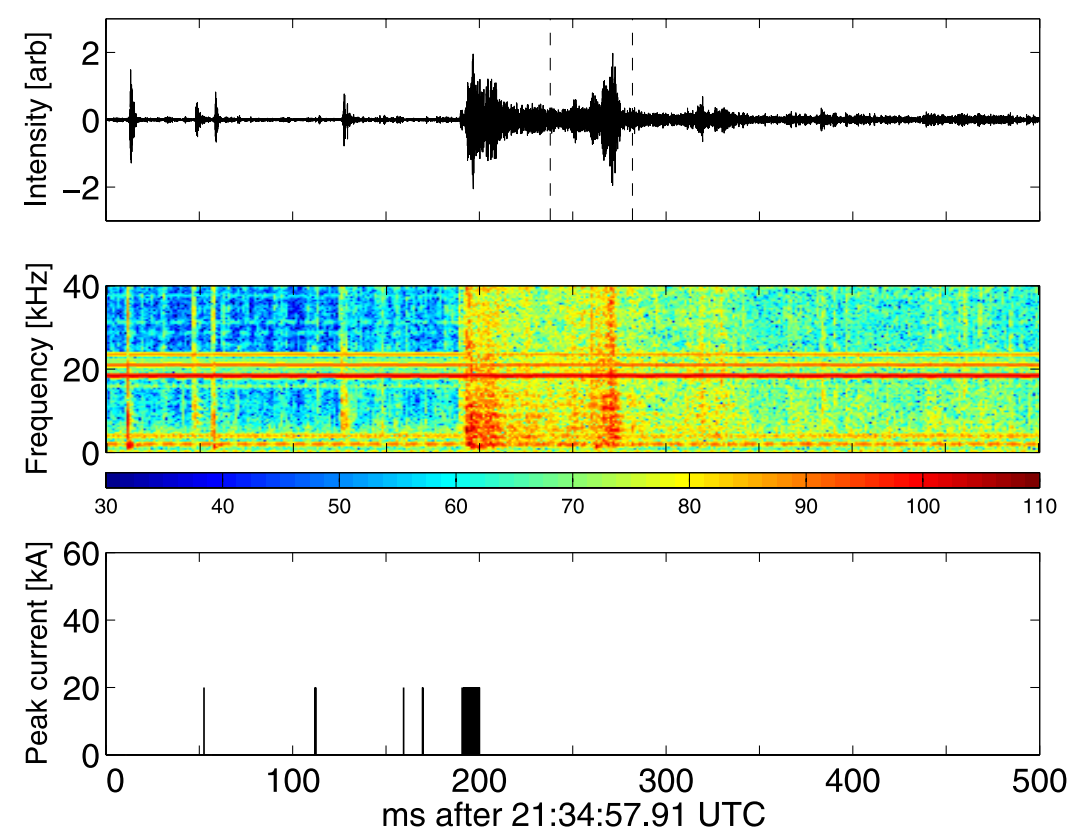

Figure 5. Same as in Figure 2 but for the sprite event of 23 July 2003, 2134:58 UTC, for which Météorage did not detect any causative $+\mathrm{CG}$ stroke (Figure 1, right). Displayed is the east-west component of the signal.

report maximum delays of about $200 \mathrm{~ms}$ [São Sabbas et al., 2003] and $280 \mathrm{~ms}$ [Mika et al., 2005].

[22] The ELF/VLF and VHF activity for this event is shown in Figure 5. The lower panel shows the cluster of VHF lightning sources (black column) occurring nearly simultaneously with the onset of a strong cluster of ELF/ VLF sferics. The ELF/VLF activity was not associated with any cloud-to-ground lightning detected by the two networks and the question is if a $+\mathrm{CG}$ stroke (and IC activity) was missed because the waveforms were too complex [Reising et al., 1996]. The presence of strong ELF/VLF sferic activity may support this suggestion. In addition, the impulsive rise in the north-south ELF/VLF signal at the onset of the event is possibly due to an undetected return stroke, whereas the smoother rise observed in the east-west component (Figure 5) is rather characteristic for cloud flashes. While we cannot exclude that an undetected $+\mathrm{CG}$ return stroke triggered the sprites, the data underscore the importance of IC lightning activity in sprite generation.

\subsection{Other Events and Nonevents}

[23] VHF sources were not detected for events $1,6,8,9$, and 15 . For events 1 and 15 this was likely due to decreased detection efficiency since the storm was located rather far from the SAFIR antennas.

[24] The delays between the causative +CGs and events 6 and 8 were rather long (159 $\mathrm{ms}$ and $123 \mathrm{~ms})$ with no accompanying VHF activity in spite of being located at optimum detection range. However, the ELF/VLF band did show long-lasting sferic clusters (around $200 \mathrm{~ms}$ ) after the $+\mathrm{CG}$, similar to those observed with carrots. We could not easily identify the type of these two sprites: event 6 consisted of three grouped small carrot-like elements. They seemed to occur closer to the camera than the preceding sprites, or alternatively, higher in altitude. The second frame showed many small elements shaped like a fan. Event 8 looked somewhat similar, more blobby, and clouds may have obscured part of this sprite.

[25] The two non-sprite-producing +CG flashes (at 2154:19.114 UTC and 2158:08.133 UTC) that occurred in the same region and period as events $4-8$ showed no signature of sferic clusters. This result may indicate that extensive IC breakdown did not occur and that the process of supply of continuing current of charge to ground was not present [Bell et al., 1998].

\section{Discussion}

[26] The general characteristics of the observations, valid for the events of this particular storm system, can be summarized as:

[27] 1. The IC and CG lightning characteristics, reflected in both the VHF and ELF/VLF bands, have different characteristics for column and carrot sprites.

[28] 2. Column sprites are triggered by $+\mathrm{CG}$ discharges with relatively high peak currents and with short delays between the $+\mathrm{CG}$ and the sprite (on average $\sim 12 \mathrm{~ms}$ relative to the start of the video frame integration time of $20 \mathrm{~ms})$. In contrast, carrot sprites are triggered by $+\mathrm{CG}$ discharges with smaller peak currents and longer delays ( $\sim 20$ to $200 \mathrm{~ms}$ ). We did not find a relationship between the $+\mathrm{CG}$ peak current and the number of columns observed [Adachi et al., 2004]

[29] 3. Column sprites are associated with little or no IC lightning activity while carrot sprites are associated with bursts of IC activity. For carrot sprites, the VHF sources are observed $\sim 25$ to $75 \mathrm{~ms}$ prior to the causative $+\mathrm{CG}$ discharge. For both sprite categories, ELF/VLF sferic activity is observed following the causative $+\mathrm{CG}$ flash. Sferic 
activity is short-lived ( $<30 \mathrm{~ms})$ for column sprites and long lasting ( $\sim 45$ to $250 \mathrm{~ms}$ ) for carrot sprites.

[30] 4. The SAFIR system rarely observed VHF sources after the sprite-related $+\mathrm{CG}$ stroke. However, ELF/VLF sferics, persisting up to several hundred milliseconds, were always observed after the $+\mathrm{CG}$ return stroke.

[31] 5. Observations suggest that some carrot sprites may be caused exclusively by IC discharges.

[32] The data presented herein show that the intracloud phase of a lightning flash plays an important role in the generation of carrot sprites but appears relatively unimportant for column sprites. This result may indicate that carrot sprites are provoked by larger total charge moment changes, whereas column sprites are provoked by larger instantaneous charge moment changes during a $+\mathrm{CG}$ discharge. We hypothesize that these discharge characteristics cause the mesospheric electric field to reach higher values for column sprites, but exceeding the breakdown threshold only for a shorter duration compared to carrot sprites. This might explain the short, straight shape of column sprites, compared to the taller and more complex shape of carrot sprites that have more time to grow in vertical and horizontal directions. The results further confirm the suggestion that ELF/VLF sferic clusters are indicative of sprite-producing discharges [Johnson and Inan, 2000; Ohkubo et al., 2005], although the data do not allow a clear distinction between + CG- and IC activity.

[33] It is striking that lightning sources detected by the VHF interferometer are only seen preceding the causative $+\mathrm{CG}$ while there is also a strong ELF/VLF signature beginning at the $+\mathrm{CG}$ and persisting for up to several hundred milliseconds. We suppose that in our sprite-producing + CGs the characteristics of the in-cloud lightning processes are different after the $+\mathrm{CG}$ stroke than before. It is possible that the electromagnetic radiation caused by an abundance of in-cloud leaders renders the electromagnetic signal so complex that our SAFIR VHF interferometer system fails to identify IC lightning locations, or that the VHF radiation is too weak to be detected simultaneously at multiple stations having a long baseline. The relative insensitivity of VHF interferometers to signals from positive leaders is known [Mazur et al., 1998]. However, negative leaders propagate across positively charged regions in the cloud and supply this charge to a $+\mathrm{CG}$, so this cannot be a valid explanation in this case. The VHF sources preceding some of the sprite-producing +CGs must therefore associate with negative leader activity, either inside the clouds or between the earth and the cloud. This allows for a speculation about possible lighting processes: in the case of negative in-cloud leaders, the origin must be a negatively charged region, horizontally or vertically close to the positively charged region that delivers the $+\mathrm{CG}$. In the case of negative leaders between earth and cloud, these leaders must originate from a mountain or tall man-made construction in reaction to the electric field created by the positive charge inside the cloud. When these leaders connect to the positive charge region, one or more positive return strokes may follow, in fact a ground-to-cloud (GC) flash [e.g., Berger and Vogelsanger, 1965]. In another way a $+\mathrm{CG}$ is created when a positive leader grows from the cloud to the ground, after which a return stroke follows. In both cases the positive charge region would be neutralized by negative leaders during/after the return stroke, leading to a continuing current, which has been observed in some cases by Proctor et al. [1988]. This process would be responsible for the observed ELF/VLF sferic clusters following the $+\mathrm{CG}$ stroke. For further studies it would certainly be interesting, if not necessary, to identify exactly which lightning processes are going on, beyond the detection of a $+\mathrm{CG}$ with its peak current and its charge moment change.

[34] Systems such as the Lightning Mapping Array (LMA) and the Lightning Detection and Ranging (LDAR II) systems, also operating in the VHF range but utilizing short baselines and time-of-arrival location, are capable of showing extensive horizontal channels, known as spider lightning [e.g., Mazur et al., 1998; Lang et al., 2004b; Carey et al., 2005]. It appears worthwhile to compare these systems with broadband ELF/ VLF observations to test if long-duration sferic clusters are indeed signatures of spider lightning. We found the ELF/VLF clusters to last only up to $0.2-0.3 \mathrm{~s}$, which is much shorter than the 1-3 s duration of a spider lightning discharge observed in the referred studies above. It may indicate smaller horizontal extension of the intracloud flashes in our storm, which may be related to the relatively small size compared to the average storm in the High Plains region of the United States [Lyons et al., 2006]. A long-lasting low-amplitude signal, not present before the $+\mathrm{CG}$, is sometimes seen to extend for longer than our graphs show (>300 ms). We may speculate that either intracloud lightning may have continued in a differently radiating phase, or the ionospheric environment was modified, possibly caused by the sprite or electromagnetic pulse, which changed the propagation of radio waves. Nevertheless, the first consistent signal received from the sprite-generating discharge in our events was the $+\mathrm{CG}$, or a weak signal preceding the $+\mathrm{CG}$ by only $25-75 \mathrm{~ms}$, whereas in the work of Stanley [2000] an initial cloud discharge was already starting $0.5-1.5 \mathrm{~s}$ before the $+\mathrm{CG}$. Since our SAFIR data do not show extensive horizontal discharges and signals after the time of the +CGs, we could not verify the phenomenon of sprites occurring at the periphery of a developing cloud discharge.

[35] A study of ELF/VLF sferic characteristics for the events of other sprite-producing storm systems, and also of the $+\mathrm{CG}$ discharges that did not produce sprites, is on the way. Further studies of IC lightning detection measurements with nearby broadband ELF/VLF recordings will certainly be useful in validating the detection efficiency of lightning locating systems like SAFIR which employ VHF-band interferometry or time-of-arrival techniques.

[36] Acknowledgments. This study was supported by the Research Training Network "Coupling of Atmospheric Layers" (CAL), sponsored by the EU FP5 program. We thank Thomas Allin for his efforts in recording the 2003 sprite data. The lightning detection data came from two different companies. We thank Stephane Pedeboy of Météorage for the extended network data and Jean-Yves Lojou of Vaisala for the SAFIR data. The authors are grateful to Météo France for providing weather radar data. Stanford participation is supported by the National Science Foundation.

\section{References}

Adachi, T., H. Fukunishi, Y. Takahashi, and M. Sato (2004), Roles of the EMP and QE field in the generation of columniform sprites, Geophys. Res. Lett., 31, L04107, doi:10.1029/2003GL019081.

Bell, T. F., S. C. Reising, and U. S. Inan (1998), Intense continuing currents following positive cloud-to-ground lightning associated with red sprites, Geophys. Res. Lett., 25, 1285. 
Berger, K., and E. Vogelsanger (1965), Messungen und Resultate der Blitzforschung der Jahre 1955-1963 auf dem Monte San Salvatore, Bull. Schweiz. Elektrotech., 56, 2-22.

Boccippio, D. J., E. R. Williams, S. J. Heckman, W. A. Lyons, I. T. Baker, and R. Boldi (1995), Sprites, ELF transients, and positive ground strokes, Science, 269, 1088.

Carey, L. D., M. J. Murphy, T. L. McCormick, and N. W. S. Demetriades (2005), Lightning location relative to storm structure in a leading-line, trailing-stratiform mesoscale convective system, J. Geophys. Res., 110, D03105, doi:10.1029/2003JD004371.

Cummer, S. A., and W. A. Lyons (2005), Implications of lightning charge moment changes for sprite initiation, J. Geophys. Res., 110, A04304, doi:10.1029/2004JA010812.

Cummins, K. L., M. J. Murphy, E. A. Bardo, W. L. Hiscox, R. B. Pyle, and A. E. Pifer (1998), NLDN'95, A combined TOA/MDF technology upgrade of the US National Lightning Detection Network, J. Geophys. Res., 103, 9035.

Franz, R. C., R. J. Nemzek, and J. R. Winckler (1990), Television image of a large upward electrical discharge above a thunderstorm system, Science, 249, 48.

Füllekrug, M., and S. C. Reising (1998), Excitation of Earth-ionosphere cavity resonances by sprite-associated lightning flashes, Geophys. Res. Lett., 25, 4145.

Johnson, M. P., and U. S. Inan (2000), Sferic clusters associated with Early/ Fast VLF Events, Geophys. Res. Lett., 27, 1391.

Hu, W., S. A. Cummer, W. A. Lyons, and T. E. Nelson (2002), Lightning charge moment changes for the initiation of sprites, Geophys. Res. Lett. 29(8), 1279, doi:10.1029/2001GL014593.

Lang, T. L., et al. (2004a), The Severe Thunderstorm Electrification and Precipitation Study (STEPS), Bull. Am. Meteorol. Soc., 85, 1107.

Lang, T. J., S. A. Rutledge, and K. C. Wiens (2004b), Origins of positive cloud-to-ground lightning flashes in the stratiform region of a mesoscale convective system, Geophys. Res. Lett., 31, L10105, doi:10.1029/ 2004GL019823.

Lyons, W. A., T. E. Nelson, R. A. Armstrong, V. P. Pasko, and M. A. Stanley (2003a), Upward electrical discharges from thunderstorm tops, Bull. Am. Meteorol. Soc., 84, 445.

Lyons, W. A., E. R. Williams, S. A. Cummer, and M. A. Stanley (2003b), Characteristics of sprite-producing positive cloud-to-ground lightning during the 19 July 2000 STEPS mesoscale convective systems, Mon. Weather Rev., 131, 2417.

Lyons, W. A., L. M. Andersen, T. E. Nelson, and G. R. Huffines (2006), Characteristics of sprite-producing electrical storms in the STEPS 2000 domain, paper presented at 2nd Conference on Meteorological Applications of Lightning Data, Am. Meteorol. Soc., Atlanta.

Mazur, V., X.-M. Shao, and P. R. Krehbiel (1998), "Spider" lightning in intracloud and positive cloud-to-ground flashes, J. Geophys. Res., 103, 19,811 .

Mika, A., C. Haldoupis, R. A. Marshall, T. Neubert, and U. S. Inan (2005), Subionospheric VLF signatures and their association with sprites observed during EurosSprite 2003, J. Atmos. Sol. Terr. Phys., 67,1580 .
Neubert, T. (2003), On sprites and their exotic kin, Science, 300, 747.

Neubert, T., et al. (2005), Co-ordinated observations of transient luminous events during the EuroSprite2003 campaign, J. Atmos. Sol. Terr. Phys., 67,807 .

Ohkubo, A., H. Fukunishi, Y. Takahashi, and T. Adachi (2005), VLF/ELF sferic evidence for in-cloud discharge activity producing sprites, Geophys. Res. Lett., 32, L04812, doi:10.1029/2004GL021943.

Pasko, V. P., U. S. Inan, T. F. Bell, and Y. N. Taranenko (1997), Sprites produced by quasi-electrostatic heating and ionization in the lower ionosphere, J. Geophys. Res., 102, 4529.

Proctor, D. E., R. Uytenbogaardt, and B. M. Meredith (1988), VHF radio pictures of lightning flashes to ground, J. Geophys. Res., 93, 12,683.

Reising, S. C., U. S. Inan, and T. F. Bell (1996), Evidence for continuing current in sprite-producing cloud-to-ground lightning, Geophys. Res. Lett., 23, 3639.

Richard, P., and J. Y. Lojou (1996), Assessment of application of storm cell electrical activity monitoring to intense precipitation forecast, paper presented at 10th International Conference on Atmospheric Electricity, Int. Comm. of Atmos. Electr., Osaka, Japan.

Rycroft, M. J., and M. Cho (1998), Modelling electric and magnetic fields due to thunderclouds and lightning from cloud-tops to the ionosphere, J. Atmos. Terr. Phys., 60, 889.

São Sabbas, F. T., D. D. Sentman, E. M. Wescott, O. Pinto Jr., O. Mendes Jr., and M. J. Taylor (2003), Statistical analysis of space-time relationships between sprites and lightning, J. Atmos. Sol. Terr. Phys., 65, 525.

Stanley, M. A. (2000), Sprites and their parent discharges, Ph.D. dissertation, 163 pp., N. M. Inst. of Mining and Technol., Socorro, N. M.

Valdivia, J. A., G. Milkh, and K. Papadopoulos (1997), Red sprites: Lightning as a fractal antenna, Geophys. Res. Lett., 24, 3169.

Wescott, E. M., H. C. Stenbaek-Nielsen, D. D. Sentman, M. J. Heavner, and F. T. São Sabbas (2001), Triangulation of sprites, associated halos and their possible relation to causative lightning and micro-meteors, J. Geophys. Res., 106, 10,467.

Williams, E. R. (1998), The positive charge reservoir for sprite-producing lightning, J. Atmos. Sol. Terr. Phys., 60, 689.

Wilson, C. T. R. (1925), The electric field of a thundercloud and some of its effects, Proc. Phys. Soc. London, 37, 32D.

Wood, T. G., and U. S. Inan (2002), Long-range tracking of thunderstorms using sferic measurements, J. Geophys. Res., 107(D21), 4553, doi:10.1029/2001JD002008.

C. Haldoupis and Á. Mika, Department of Physics, University of Crete, Iraklion, Crete, GR-71003 Greece.

U. S. Inan, STAR Laboratory, Stanford University, Stanford, CA $94305-$ 9515, USA.

T. Neubert, Danish National Space Center, Juliane Maries Vej 30, DK2100 Copenhagen, Denmark.

S. Soula and O. A. van der Velde, Laboratoire d'Aérology, Observatoire Midi-Pyrénées (CNRS/UPS), 14 Avenue Edouard Belin, F-31400 Toulouse, France. (vdvo@aero.obs-mip.fr) 